\title{
TROMBOSIS VENOSA INTRACRANEAL: SIGNOS IMAGINOLÓGICOS Y ERRORES FRECUENTES
}

\author{
Drs. Michael Hirsch $\boldsymbol{S}^{(1)}$, Alejandra Torres $\mathbf{G}^{(2)}$.
}

1. Residente de Radiología, Hospital Clínico Universidad de Chile. Santiago, Chile.

2. Neurorradióloga, Hospital Clínico Universidad de Chile. Santiago, Chile.

\section{INTRACRANIAL VENOUS THROMBOSIS: IMAGING SIGNS AND COMMON ERRORS}

\begin{abstract}
Although intracranial venous thrombosis is a relatively rare disease, it constitutes an entity that must be timely and accurately diagnosed in emergency services, given the need for prompt treatment to avoid serious complications, including neurological deficits or even death. There are several imaging signs provided by both $C T$ and magnetic resonance imaging scans that allow this early diagnosis. On the other hand, some differential diagnoses need to be performed to prevent the error of mistaking intracranial venous thrombosis for any other entity.

Key words: Cranial sinuses, Intracranial, Magnetic resonance imaging, Sinus thrombosis, Spiral computed tomography, Radiology, Tomography.
\end{abstract}

Resumen: Si bien la trombosis venosa intracraneal es una patología relativamente poco frecuente, es una entidad que debe ser diagnosticada a tiempo y con certeza en los servicios de urgencia, dada la necesidad de pronto tratamiento para evitar complicaciones graves que incluyen déficit neurológicos e incluso muerte. Existen varios signos imaginológicos que nos permiten hacer este diagnóstico, tanto en tomografía computarizada como en resonancia magnética. Por otra parte, es necesario considerar algunos diagnósticos diferenciales para no cometer errores, confundiendo esta patología con otras entidades.

Palabras clave: Senos craneales, trombosis de los

Hirsch M. Trombosis venosa intracraneal: Signos imaginológicos y errores frecuentes. Rev Chil Radiol 2010; 16(4): 175- 187.

Correspondencia: Dr. Michael Hirsch S.

mphirsch@gmail.com

Trabajo recibido el 26 de abril de 2010, aceptado para publicación el 28 de octubre de 2010. senos craneales, intracraneal, tomografía, tomografía espiral computarizada, resonancia magnética, radiología.

\section{Introducción}

La trombosis venosa intracraneal (TVI), es una patología cerebrovascular que puede afectar a todas las edades; se presenta predominantemente en los neonatos y adultos alrededor de la tercera década ${ }^{(1,2)}$. Puede incluir tanto venas cerebrales (VC) como senos venosos durales (SVD). Existen más de cien causas descritas como factor etiopatogénico de TVI (Tabla I) ${ }^{(1)}$, que se pueden resumir en la clásica "Tríada de Virchow", que corresponde a estados de hipercoagulabilidad, daño de la pared vascular y alteración del flujo venoso ${ }^{(3)}$. Sin embargo, realizando todos los exámenes y pruebas de laboratorio disponibles, sólo es posible encontrar el factor causal entre 75 a $85 \%$ de los pacientes ${ }^{(1,4)}$.

Una revisión de la presentación clínica de la TVI da cuenta de una variada gama de síntomas y signos, que van desde la cefalea y la hipertensión intracraneal hasta el coma y la muerte (Tabla II). La cefalea es el síntoma más frecuente y se produce en el 75 a $95 \%$ de los pacientes con TVI, habitualmente precediendo al desarrollo de otras alteraciones neurológicas (70-75\%) por días, semanas o excepcionalmente meses ${ }^{(2,5)}$ asociándose a manifestaciones de hipertensión intracraneal en un 20 a $40 \%$ de los $\operatorname{casos}^{(2)}$. La cefalea puede ser de intensidad variable, con frecuencia grave y predominantemente difusa ${ }^{(2)}$. Dada la variabilidad e inespecificidad de los síntomas de presentación de la TVI se hace necesario contar con un método de diagnóstico por imágenes para demostrar la etiología de los síntomas, en especial porque el diagnóstico precoz permite instaurar un tratamiento anticoagulante en forma oportuna, reduciendo la tasa de complicaciones y secuelas neurológicas. 
Tabla I. Causas y factores de riesgo asociados con trombosis venosa intracraneal.

\section{Condiciones genéticas protrombóticas}

Deficiencia de antitrombina

Deficiencia de proteínas $\mathrm{C}$ y $\mathrm{S}$

Mutación del factor $\mathrm{V}$ de Leiden

Mutaciones de la protrombina

Homocisteinemia causada por mutaciones en el gen de la metiltetrahidrofolato reductasa

Condiciones protrombóticas adquiridas

Síndrome nefrótico

Anticuerpos antifosfolípidos

Homocisteinemia

Embarazo

Puerperio

\section{Infecciones}

Otitis, mastoiditis, sinusitis

Meningitis

Enfermedad infecciosa sistémica

Enfermedades inflamatorias

Lupus eritematoso sistémico

Granulomatosis de Wegener

Sarcoidosis

Enfermedad inflamatoria intestinal

Síndrome de Behçet

Condiciones hematológicas

Policitemia, primaria y secundaria

Trombocitemia

Leucemia

Anemia, incluye hemoglobinuria paroxística nocturna

\section{Drogas}

Anticonceptivos orales

Asparaginasa

Causas mecánicas, traumáticas

Traumatismo cefálico

Lesión en senos o vena yugular, cateterismo yugular

Procedimientos neuroquirúrgicos

Punción lumbar

\section{Misceláneos}

Deshidratación, especialmente en los niños

Cáncer

Tabla II. Características clínicas de la trombosis venosa intracraneana.

\section{Síntomas}

\section{Cefalea}

Alteraciones visuales

Compromiso de conciencia

Náuseas, vómitos

\section{Signos}

Papiledema

Déficit neurológico focal

Parálisis de pares craneales

Convulsiones, coma

\section{Aspectos imaginológicos}

Existen varios hallazgos imaginológicos que nos permiten hacer o sospechar el diagnóstico de TVI, tanto en tomografía computada (TC) como resonancia magnética $(\mathrm{RM})$ :
a) Signos se oclusión venosa
b) Alteraciones parenquimatosas y otros cambios secundarios al estasis venoso
c) Signos de recanalización.

A continuación analizaremos cada uno de ellos:

\section{A) Signos de oclusión venosa \\ Signo del delta vacío}

Este hallazgo fue descrito originalmente en cortes axiales de TC con contraste endovenoso; corresponde a un defecto de llene triangular, hipodenso, en relación a un área periférica hiperdensa, que se produce por el realce del medio de contraste en un seno sagital superior (SSS) trombosado (Figura 1) ${ }^{(3,6)}$. En la actualidad, mediante reconstrucciones multiplanares con TC multidetector es posible observar este signo no sólo en el SSS, sino también en el seno transverso (ST) y sigmoideo (SS), también en estudios contrastados con RM.
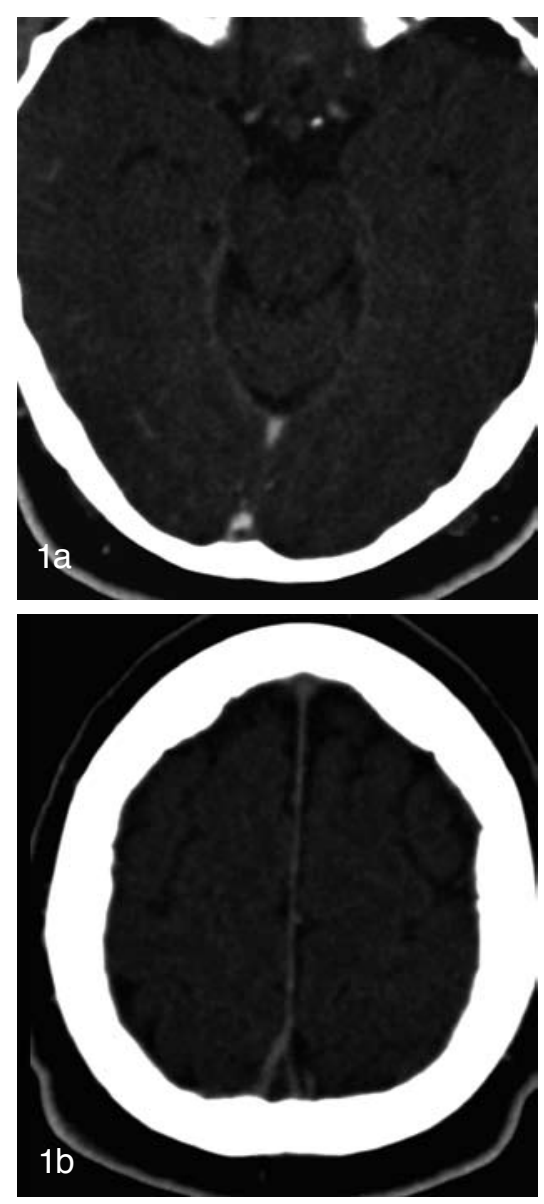

Figura 1. TC con contraste $(a, b)$ en que se identifica signo del delta vacío en seno sagital superior a distintos niveles en un mismo paciente. 
Los SVD tienen una forma alargada y triangular al seccionarlos, no poseen válvulas y poseen un plexo venoso adyacente que actúa como vía colateral para el drenaje, en caso de trombosis (Figura 2) ${ }^{(7)}$.

Se han mencionado numerosas hipótesis que intentan explicar la apariencia de este signo. Entre ellas encontramos:

(a) Recanalización del trombo dentro del seno

(b) Organización del coágulo

(c) Alteración de la barrera hematoencefálica

(d) Dilatación de colaterales venosas durales y peridurales.

Al parecer, esta última sería la explicación más plausible debido a que la circulación venosa colateral a nivel dural consiste principalmente en lagunas laterales, redes vasculares (espacios cavernosos durales), venas meníngeas tributarias y el realce de estas estructuras con el medio de contraste produciría el signo del delta vacío en el seno trombosado ${ }^{(3,6,7)}$.

Hasta en un $90 \%$ de los casos la localización de la trombosis compromete más de un seno, particularmente el ST y SS, denominados en conjunto seno lateral (Tabla III) ${ }^{(4,8,9)}$.
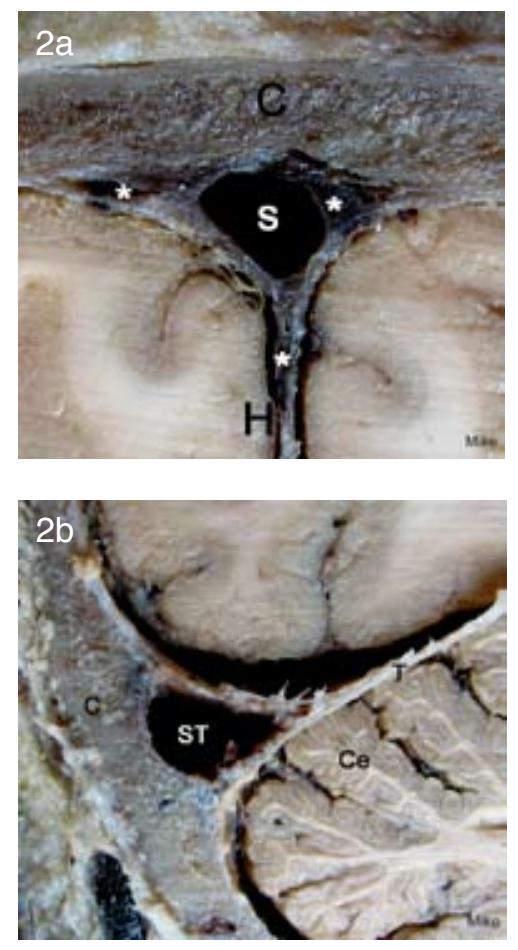

Figura 2. Cortes coronales de preparados anatómicos. a) Se identifica seno sagital superior (S), formado por la divergencia de las láminas perióstica y meníngeas de la dura madre. Estas últimas convergen en la hoz del cerebro (H). Alrededor del seno existe un plexo venoso colateral (asteriscos). b) En el seno transverso (ST) las láminas meníngeas de la dura madre convergen en la tienda del cerebelo $(T)$, dándole también un aspecto triangular. Calota $(\mathrm{C})$, cerebelo $(\mathrm{Ce})$.

\section{Tabla III.}

\section{Localización del trombo}

Seno sagital superior

Seno lateral izquierdo

Seno lateral derecho

Seno recto

Venas corticales

Sistema venoso profundo

Venas cerebelares

$\%$

62,0

44,7

41,2

18,0

17,1

10,9

0,3

La TC con contraste en fase tardía ha demostrado ser un método fiable para investigar las estructuras venosas cerebrales (especialmente realizando reformateo multiplanar), con una sensibilidad del $95 \%$ en comparación con la angiografía en varias publicaciones $^{(10)}$, lo que permite obtener un buen rendimiento evitando los riesgos inherentes al procedimiento intervencional.

El signo de delta vacío se presenta en un $25 \%$ a $75 \%$ de los casos de trombosis de SVD, dependiendo de los factores técnicos utilizados. Idealmente debe buscarse mediante reconstrucciones en los distintos planos espaciales, en especial en la porción horizontal del SSS y del ST (Figura 3) y con una configuración de ventana más amplia que las que normalmente se utilizan para parénquima cerebral, con un ancho de ventana de $260 \mathrm{UH}$ y nivel de $130 \mathrm{UH}$ (Figura 4) ${ }^{(5)}$. Debe tenerse en consideración que el signo del delta vacío puede desaparecer en las etapas crónicas por el realce del coágulo organizado(5).

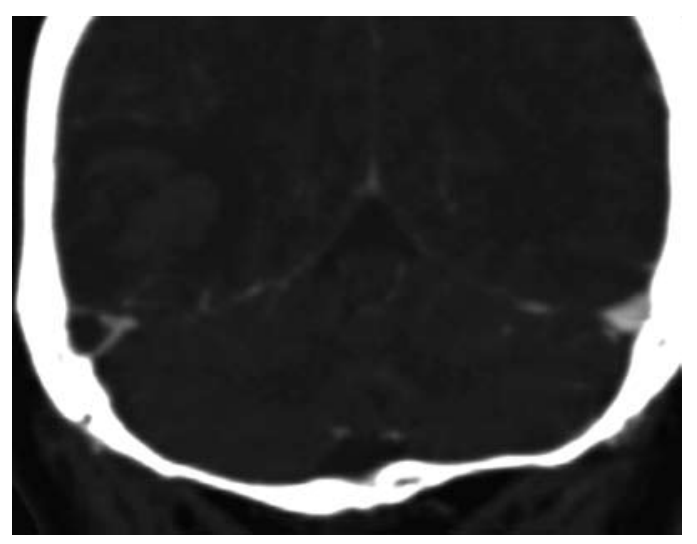

Figura 3. TC con contraste, reconstrucción en plano coronal. Se identifica signo del delta vacío en seno transverso derecho; comparar con seno contralateral. 

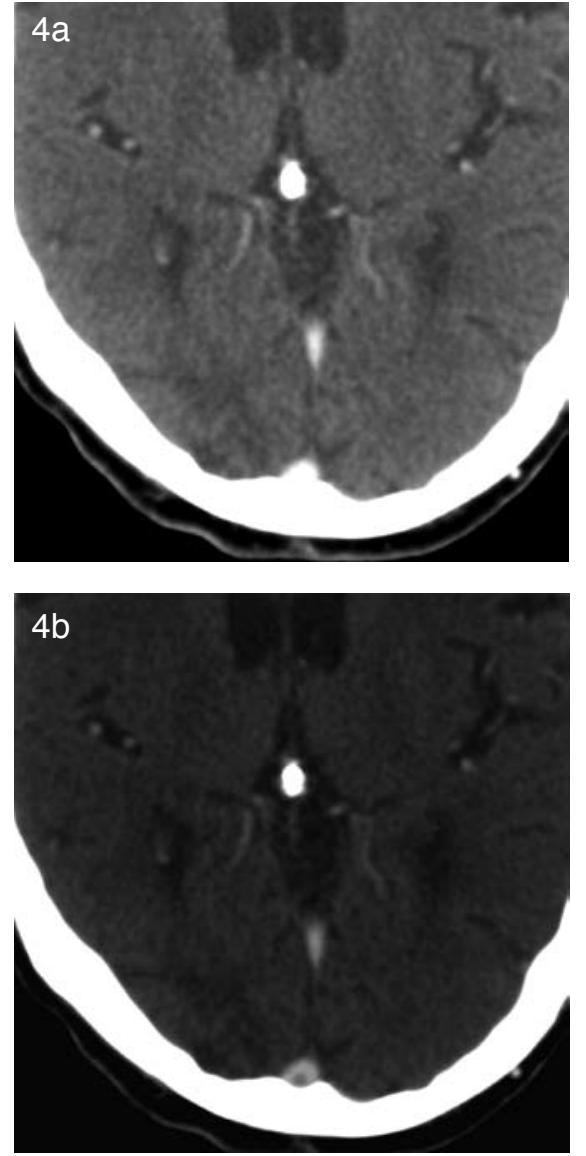

Figura 4. TC con contraste en que solo es posible apreciar un pequeño trombo en el seno sagital superior modificando el ancho y nivel de ventana.

\section{Signos del seno hiperdenso y de la cuerda}

En un $20 \%$ de los casos se puede observar el trombo en sus fases iniciales a nivel de los SVD ${ }^{(6)}$. como una imagen hiperdensa en TC sin contraste (Figuras 5, 6a, 7a), ya que el trombo se retrae disminuyendo su contenido de agua y aumentando la concentración de hemoglobina, por lo que alcanza una atenuación de 50-80 UH, lo que se normaliza en 1-2 semanas ${ }^{(11)}$. La tienda del cerebelo y los artefactos de endurecimiento del haz provocados por los huesos pueden ocultar este hallazgo o puede confundirse con una hemorragia subaracnoidea, un hematoma subdural subyacente, o ser provocado por un hematocrito elevado(11).

El signo de la cuerda es el mismo principio que el del seno hiperdenso, aplicado a las venas corticales (Figura 7a) que raramente se ven comprometidas en forma aislada en una TVI(4).

\section{Ausencia del vacío de flujo y signo de la vena hiperintensa}

En imágenes por RM sin contraste, los vasos son habitualmente hipointensos en todas las secuencias debido a su flujo; ésto se denomina vacío de señal por flujo o también llamado "vacío de flujo". Cuando este vacío de señal está ausente, los vasos se tornan hiperintensos, lo que puede reflejar una trombosis (Figuras 6c, 8a). Sin embargo, el flujo lento o turbulento puede provocar alteraciones en la intensidad de señal de los SVD e inducir a error ${ }^{(4)}$. Además, los distintos estados de degradación de la hemoglobina pueden alterar la apariencia del trombo y hacerlo menos evidente, simulando la ausencia de señal por flujo que se observa normalmente(12,13). Por ejemplo, la deoxihemoglobina del trombo agudo es hipointensa en secuencias ponderadas en T2 (Figura 9), simulando el vacío de flujo normal, e isointensa en secuencias ponderadas en T1, semejándose al parénquima cerebral adyacente, por lo que puede pasar desapercibido a menos que se utilice medio de contraste, en que la presencia del signo del delta vacío permitirá hacer el diagnóstico (Figura 8b) ${ }^{(4)}$. Algo similar ocurre en secuencias angiográficas sin contraste TOF (time of flight), en que el trombo subagudo compuesto por metahemoglobina es hiperintenso, semejando la intensidad de señal con que normalmente se ve el flujo en esta secuencia. La realización de secuencias SE ponderadas en T1 permiten diferenciar el trombo hiperintenso de la normal ausencia de señal por flujo(4), así como la realización de secuencias angiográficas $3 D$ en RM con contraste, que han mejorado la resolución espacial y la visualización de defectos de llene en el sistema venoso, aumentando la sensibilidad y especificidad en comparación con las secuencias TOF sin contraste. Dentro de éstas encontramos, por ejemplo, la secuencia FLASH (fast low-angle shot) y ATECO (auto-triggered elliptic centricordered) (Figuras $7 f, 10)^{(14-17)}$.

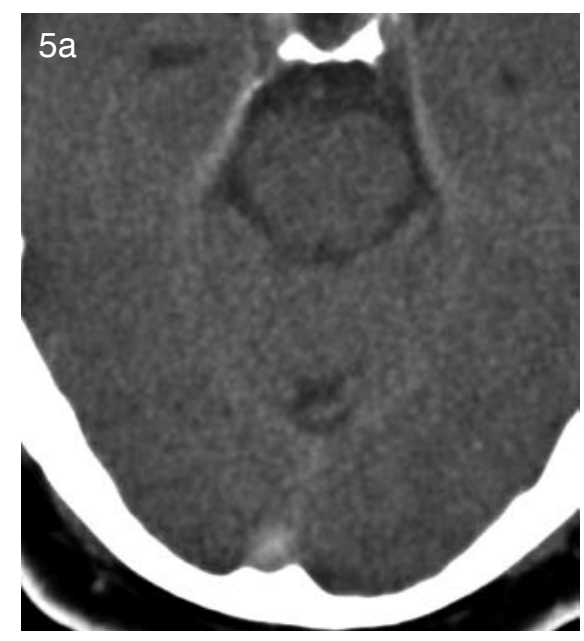




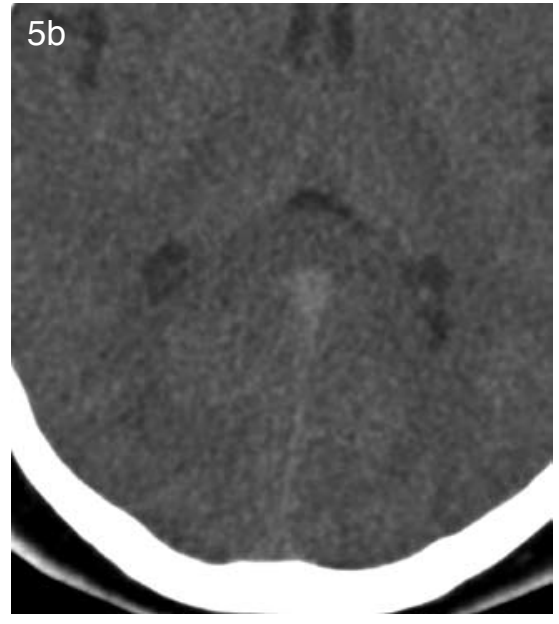

Figura 5. TC sin contraste. a) El seno sagital superior es hiperdenso. b) En un corte superior al anterior desaparece este hallazgo, lo que apoya el diagnóstico de trombosis. Nótese que la vena cerebral magna (de Galeno) si se encuentra hiperdensa en este corte.
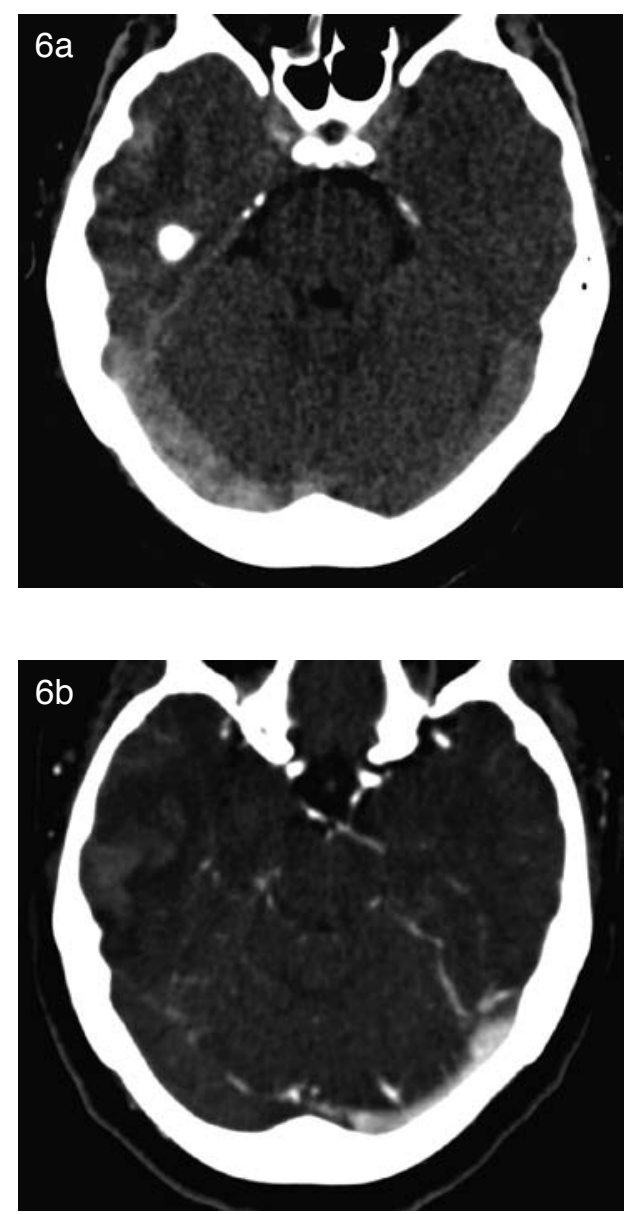
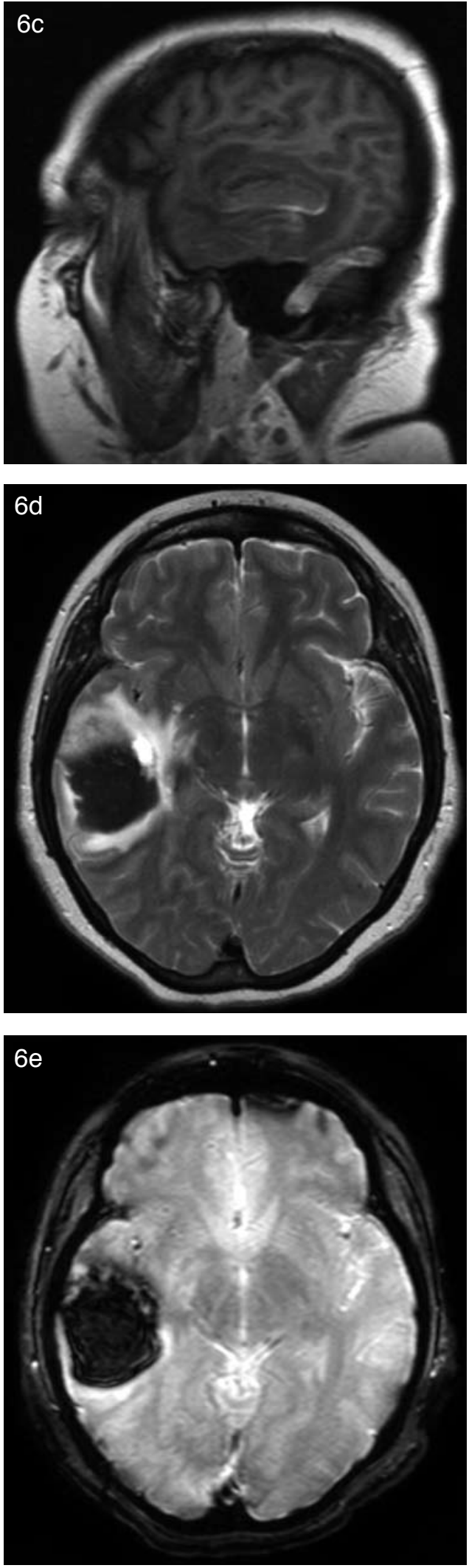

Figura 6. a) TC sin contraste que muestra seno transverso derecho hiperdenso, asociado a hematoma en lóbulo temporal, rodeado de escaso edema vasogénico. b) Tras la administración de contraste, en un corte más superior, se demuestra la ausencia de llenado del seno transverso y se visualiza mejor el hematoma. c) En secuencia T1 de RM se pone de manifiesto la ausencia del vacío de flujo normal a nivel del seno lateral y los cambios de intensidad de señal producto de la degradación de la hemoglobina en el hematoma, al igual que en secuencia T2 (d) y T2* GRE (e), apreciándose en esta última la magnificación del artefacto de susceptibilidad magnética. 
El signo de la vena hiperintensa es similar al de la cuerda observado en TC (Figura 11) y corresponde a la ausencia del vacío de flujo en las venas corticales, visible en secuencias T1 y T2 de RM, salvo cuando el estado de degradación de la hemoglobina produce hipointensidad en la señal (Figura 7c) ${ }^{(4)}$.

Lo anterior demuestra la importancia de conocer la apariencia de los distintos estados de degradación de la hemoglobina en RM, tema que es de estudio habitual en la formación de radiólogos generales y que se encuentra fuera del objetivo de esta revisión.

\section{Artefacto de susceptibilidad magnética}

Últimamente se ha dado importancia a la secuencia eco gradiente (GRE) potenciada en T2 ${ }^{*(18)}$, debido a su capacidad para resaltar el artefacto de susceptibilidad magnética que producen los estados paramagnéticos de la degradación de la hemoglobina, como la deoxihemoglobina, metahemoglobina y hemosiderina. Estos elementos se observan como imágenes hipointensas, generando el fenómeno de "blooming" que corresponde a una amplificación del área real de depósito de éstos por la magnificación del artefacto en esta secuencia (Figuras 6 y 7). Esto permite pesquisar trombosis en venas de menor calibre, como las corticales (Figura 12), o hacer evidente trombosis en las secuencias clásicas ponderadas en T1 y T2 que muchas veces, pueden pasar inadvertidas, por tener cambios sutiles de la intensidad de señal(4).

Existe una técnica con secuencia GRE 3D de alta resolución espacial con post-procesamiento de fase, que se denomina "imagen ponderada en susceptibilidad" (SWI), que amplifica el fenómeno antes descrito y en varios estudios ha demostrado ser superior a las técnicas convencionales $^{(19,20)}$.

Figura 7. Trombosis de SSS y vena cortical frontal izquierda TC sin contraste, muestra el signo del seno hiperdenso y el signo de la cuerda (a). RM muestra artefacto de susceptibilidad magnética con efecto "blooming" en secuencia T2* GRE (b), que no es evidente en la secuencia T2 (c). Compromiso del parénquima cerebral, provoca tenue hiperintensidad cortical en secuencia T2 (d) y restricción a la movilidad de los protones representada en secuencia DWI (e) y mapa $A D C$ (f). La trombosis de vena cortical se asocia a trombosis de SVD, en este caso del SSS representada en la secuencia ATECO (g). En un control a los 5 meses ya no se evidencian cambios en secuencias T2 (h), DWI (i) ni mapa $A D D$ (j) y en ATECO se evidencia recanalización del SSS (k)
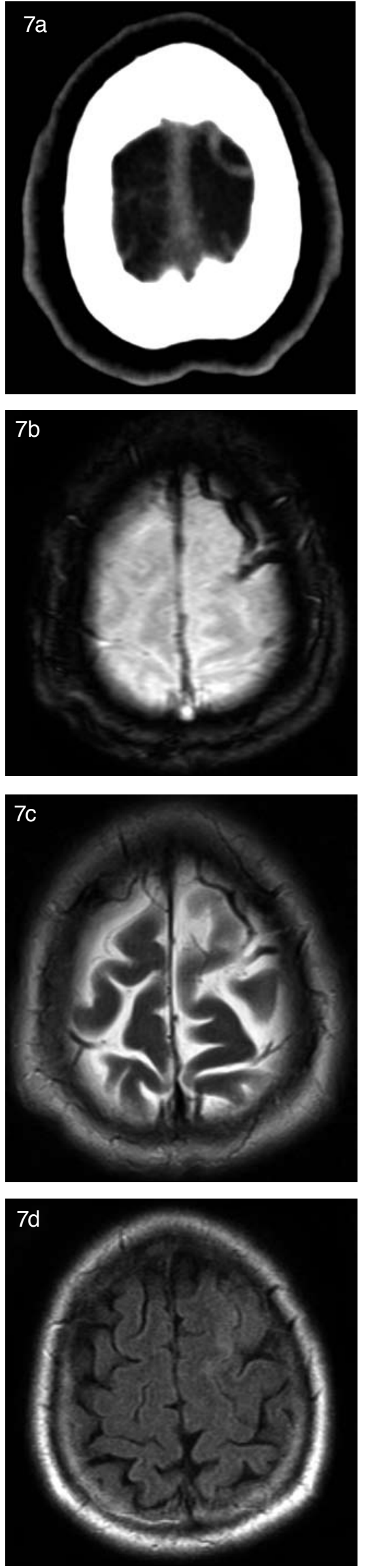

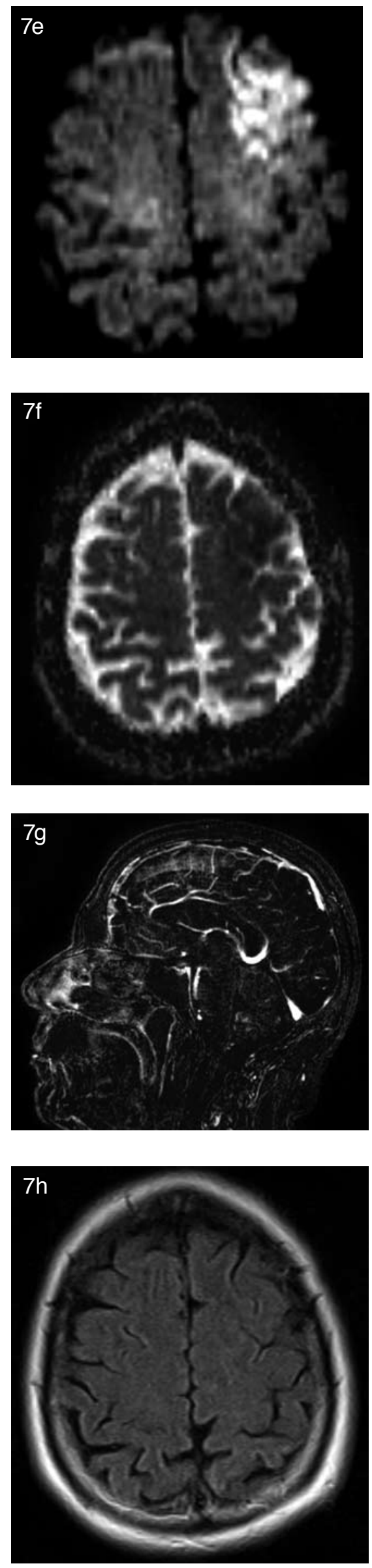
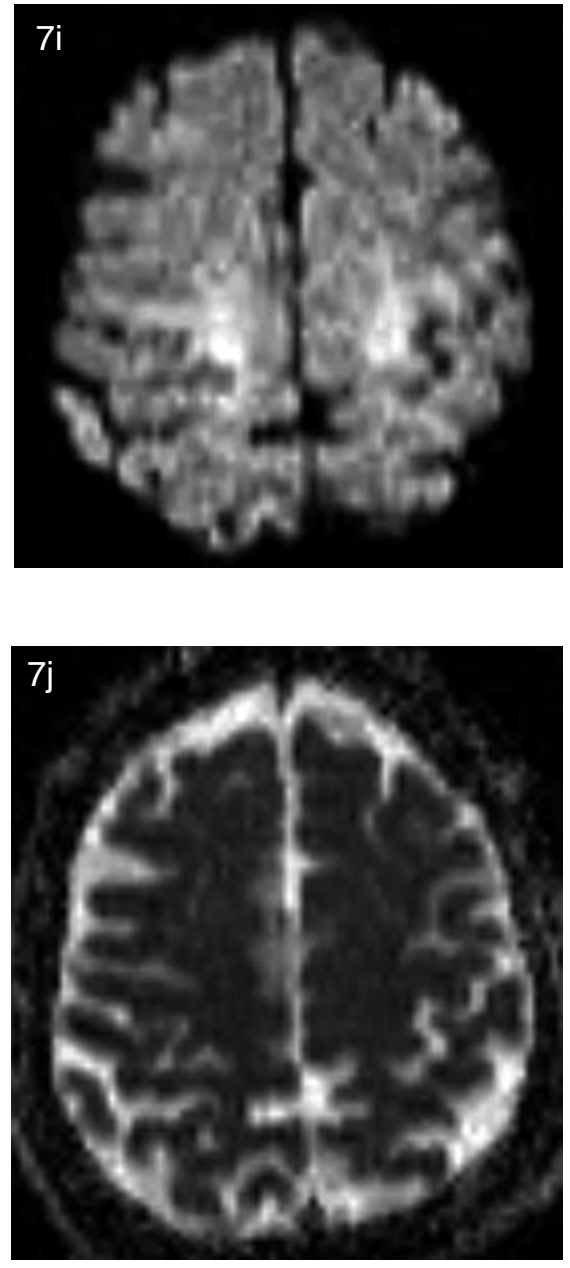

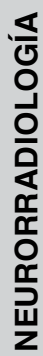

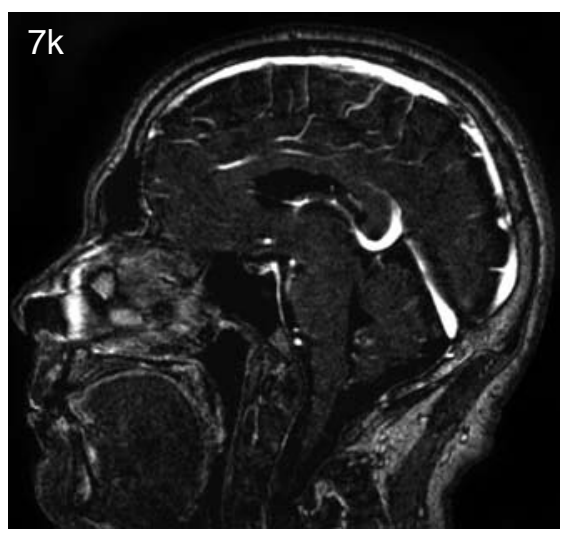

\section{B) Alteraciones parenquimatosas y otros cambios} secundarios al estasis venoso

Se pueden observar alteraciones en el parénquima cerebral entre el 50 y el $57 \%$ de los casos de $\mathrm{TVI}^{(4,21)}$, especialmente en RM. Varían en grado, tipo de alteración y reversibilidad en el tiempo; se pueden dividir en manifestaciones secundarias al edema vasogénico, secundarias a la restricción a la movilidad de los protones en secuencias potenciadas en difusión (DWI), del tipo edema citotóxico, y 
hemorrágicas ${ }^{(4)}$.

El mecanismo subyacente primario para estas alteraciones parenquimatosas es el aumento de la presión venosa secundaria a la obstrucción del drenaje venoso, lo que puede generar aumento del calibre o del número de venas visibles, especialmente en RM, y/o realce meníngeo por congestión venosa ${ }^{(5)}$. Si la presencia de vías colaterales de drenaje venoso son insuficientes, lo que es especialmente evidente en la presencia de trombosis de venas corticales, se comienza a formar edema vasogénico en el parénquima adyacente. Si la presión venosa sigue aumentando, cabe esperar la disminución consecuente de la presión de perfusión arterial y puede sobrevenir edema citotóxico y muerte celular. Si se desarrollan vías colaterales adecuadas o se produce la recanalización antes de la muerte celular o de una hemorragia intracraneal, las alteraciones parenquimatosas se pueden resolver parcial o completamente. Claramente, ésto no es un proceso lineal y frecuentemente pueden coexistir el edema vasogénico y el patrón de edema citotóxico(4); algunos autores han encontrado precozmente evidencias de edema citotóxico tras el desarrollo de una TVI por lo que su fisiopatología exacta permanece no del todo clara $^{(21)}$.

El edema cerebral, que en TC se observa como áreas hipodensas o pérdida de la diferenciación entre sustancia gris y blanca, puede ser mejor caracterizado con RM, utilizando imágenes DWl y T2 FLAIR. De esta forma podemos diferenciar una alteración de señal parenquimatosa con hiperintensidad en secuencia DWl y restricción a la movilidad de los protones en el mapa del coeficiente aparente de atenuación (ADC), similar al edema citotóxico visualizado en la isquemia arterial, pero que en la trombosis venosa se ha visto con alta probabilidad de revertir en el tiempo, lo que hace plantear que no corresponda exactamente al mismo fenómeno o, que sea una etapa reversible de éste (Figura 7)(21-23). Esta diferencia en su comportamiento con el edema citotóxico arterial hace recomendable no usar el término "infarto venoso" para este tipo de lesión parenquimatosa, ya que no refleja la potencial reversibilidad del daño(4); posiblemente es más adecuado hablar de isquemia venosa en esta situación. Algunos autores han correlacionado el grado de restricción a la movilidad de los protones con una potencial irreversibilidad cuando el coeficiente de movilidad en el mapa ADC es menor a 0,20×10-5 $\mathrm{cm}^{2} / \mathrm{s}^{(23)}$, pero este hallazgo no ha sido encontrado en otros estudios ${ }^{(25)}$.

Por otra parte, el edema vasogénico presenta hiperintensidad en secuencias T2 e hipointensidad en secuencias $\mathrm{T} 1$ con tendencia a respetar la corteza, no presenta restricción en el mapa ADC y habitualmente no es hiperintenso en difusión, al menos que represente una imagen artefactual por efecto T2 (Figura 11); generalmente se asocia a mayor efecto de masa por el aumento de la cantidad de agua en el área comprometida. El edema vasogénico es una de las alteraciones parenquimatosas más frecuentemente vistas en la TVI, lo que puede explicarse en relación a los fenómenos fisiopatológicos que se desencadenan tras la trombosis venosa intracraneal, que al aumentar la presión venosa pueden sobrepasar la barrera hematoencefálica y producir precozmente este tipo de edema, en grandes proporciones, que puede ser la alteración predominante, alcanzando hasta un tercio de los casos según algunos estudios ${ }^{(22,25)}$.

El aumento de volumen parenquimatoso sin alteración de la atenuación o señal puede encontrarse hasta en un $42 \%$ de los casos de TVI, posiblemente como reflejo de la congestión venosa capilar, con borramiento de surcos, disminución de amplitud de las cisternas y del tamaño del sistema ventricular ${ }^{(4,24)}$.

Hasta en un tercio de las TVI pueden verse signos de hemorragia intraparenquimatosa; las secuencias potenciadas en $\mathrm{T}^{*}$ son especialmente útiles para pesquisarlas ${ }^{(4)}$ pudiendo encontrarse variadas zonas de alteración de señal en el hematoma, según el estado en que se encuentre la hemoglobina (Figura 6). Debe considerarse siempre la trombosis venosa como causa de un hematoma de aspecto benigno, en que no haya otra causa aparente (hipertensión arterial, malformación vascular, etc); la búsqueda de los signos descritos es importante para sugerir o confirmar su etiología.

En las TVI, ocasionalmente se encuentra hemorragia subaracnoidea, hallazgo que ha sido escasamente publicado en la literatura aunque aparece como bastante frecuente en los estudios por punción lumbar. Descartando los casos que incluyen hematomas intraparenquimatosos que podrían tener algún grado de vaciamiento al espacio subaracnoideo, hay publicaciones que han relacionado la hemorragia subaracnoidea con la trombosis de venas corticales más frecuentemente que con la de senos venosos durales ${ }^{(25,26)}$; se ha descrito además como forma poco frecuente de presentación inicial de una trombosis venosa cortical, por lo que es importante considerar este diagnóstico entre las causas de hemorragia subaracnoidea no aneurismática(26).

\section{C) Signos de recanalización}

Cuando las TVI se comienzan a recanalizar, pueden observarse múltiples canales intrasinusales y vasos durales colaterales, principalmente en estudios venográficos por RM (Figuras $7 \mathrm{k}, 13$ ). En varios estudios se ha demostrado la utilidad del tratamiento anticoagulante y trombolítico en la recuperación y reducción de mortalidad y secuelas graves en pacientes con $\mathrm{TVI}^{(2)}$, sin embargo, la recanalización completa no es necesaria para la recuperación clínica ${ }^{(27)}$ y esta no se correlaciona directamente con la extensión de la recanalización, aparentemente por la aparición de 
colaterales que contribuirían a mejorar el drenaje de las zonas afectadas ${ }^{(4)}$. En cuanto al tiempo de recanalización, se ha demostrado que la mayoría de las recanalizaciones ocurren antes de los 6 meses y que no hay diferencia en el porcentaje de recanalización entre controles a los 3 meses y despues de los 6
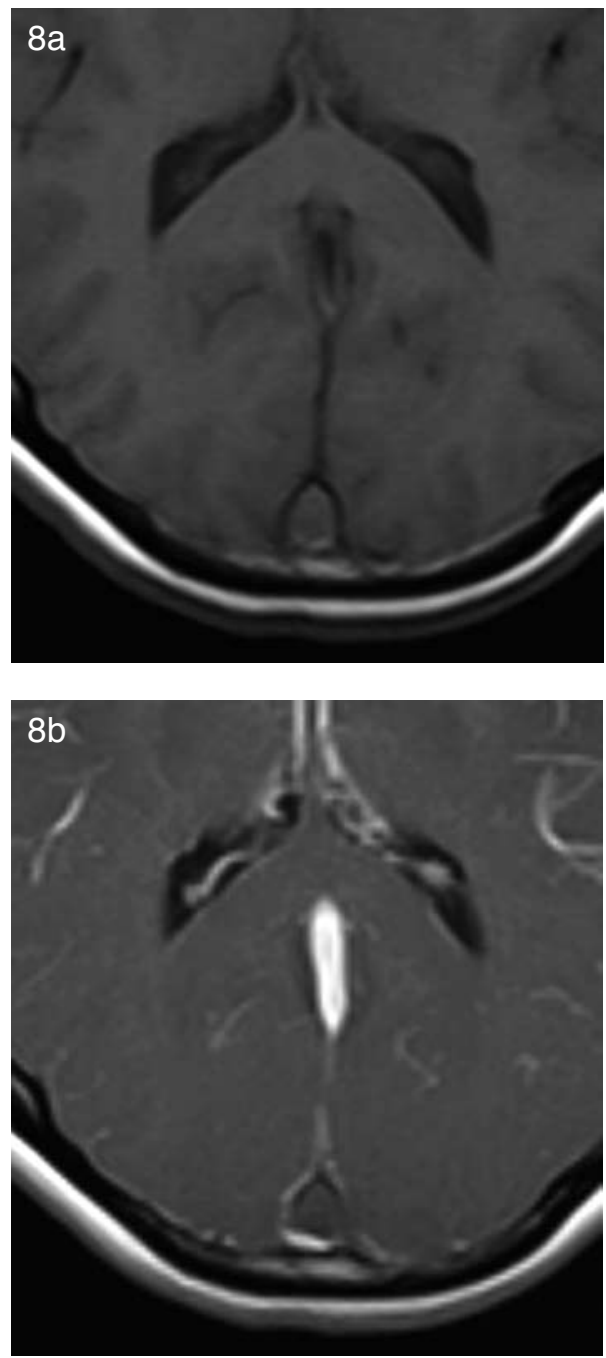

Figura 8. a) RM ponderada en T1 sin contraste muestra ausencia del vacío de flujo en el seno sagital superior. Compárese con vena cerebral magna (de Galeno) (b). La trombosis se confirmó en la secuencia con contraste.

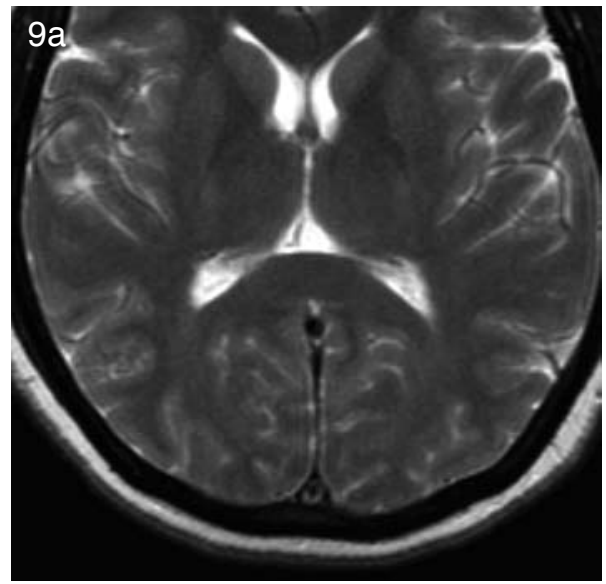

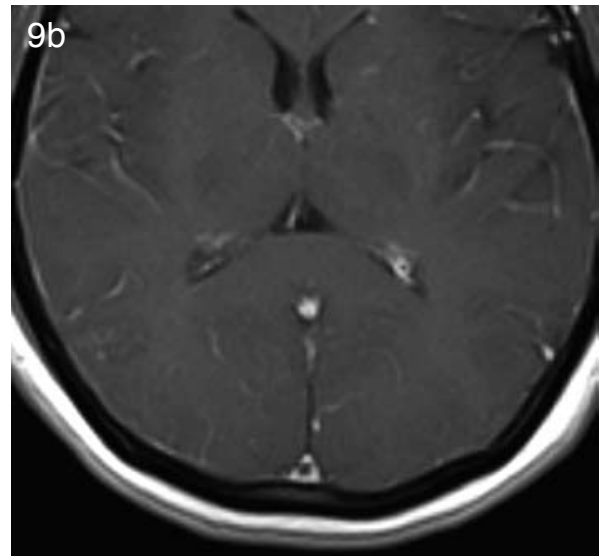

Figura 9. RM ponderada en T2 (a) y T1 con contraste (b). Nótese seno sagital superior hipointenso en T2, 10 que puede hacer pensar en un vacío de flujo normal, sin embargo tras la administración de contraste se observa signo del delta vacío.

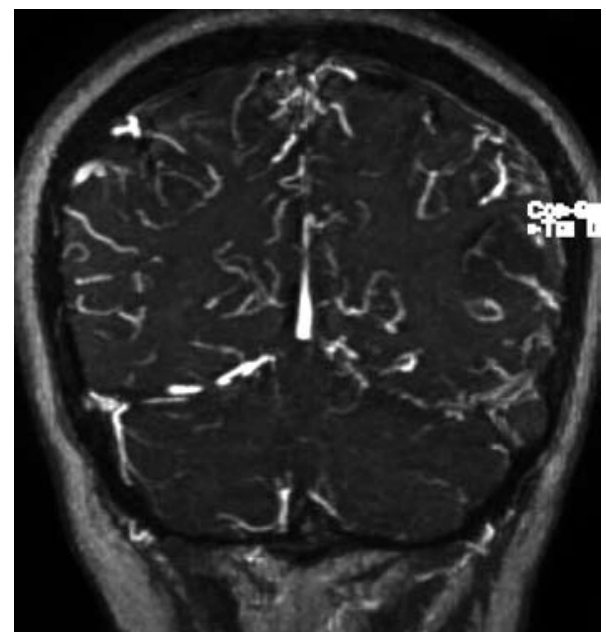

Figura 10. Secuencia ATECO de RM en plano coronal, demuestra trombosis del seno transverso izquierdo.

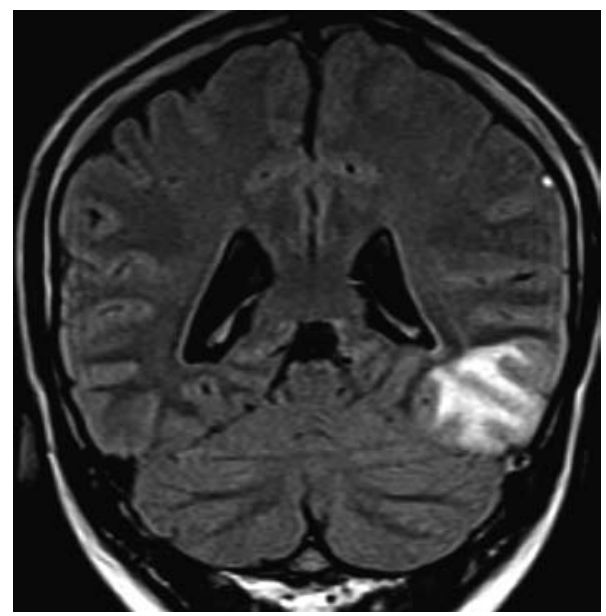

Figura 11. Secuencia T2 FLAIR muestra signo de la vena hiperintensa en una vena cortical parietal izquierda y ausencia parcial del vacío de flujo del seno transverso ipsilateral, con compromiso del lóbulo temporal, predominantemente a nivel de sustancia blanca subcortical, con el aspecto de edema vasogénico. 

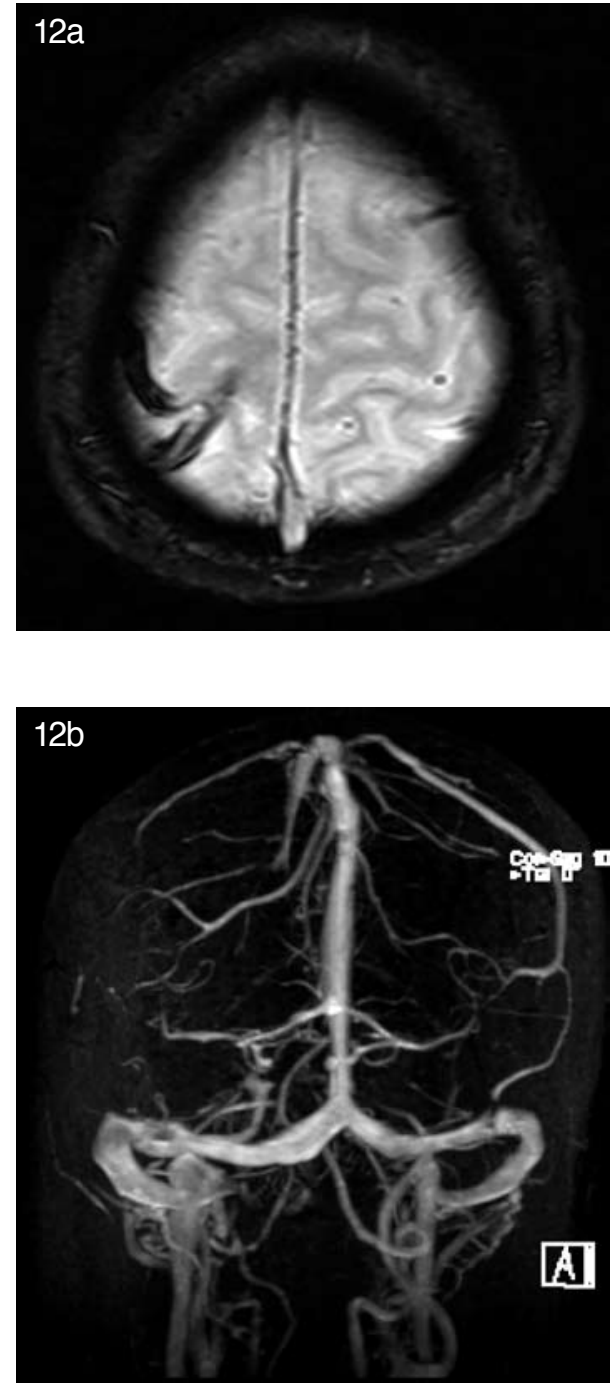

Figura 12. Secuencia $T 2 *$ GRE (a) que demuestra artefacto de susceptibilidad magnética en la vena anastomótica superior derecha (de Trolard), con falta de representación en secuencia venográfica $3 D$ (b).

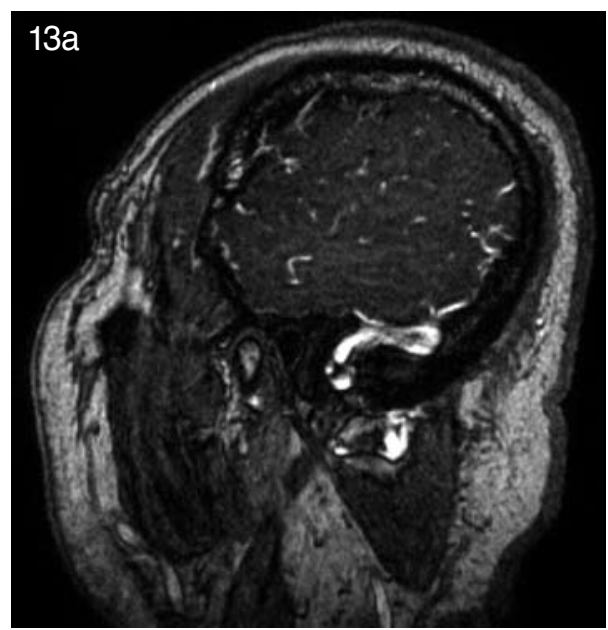

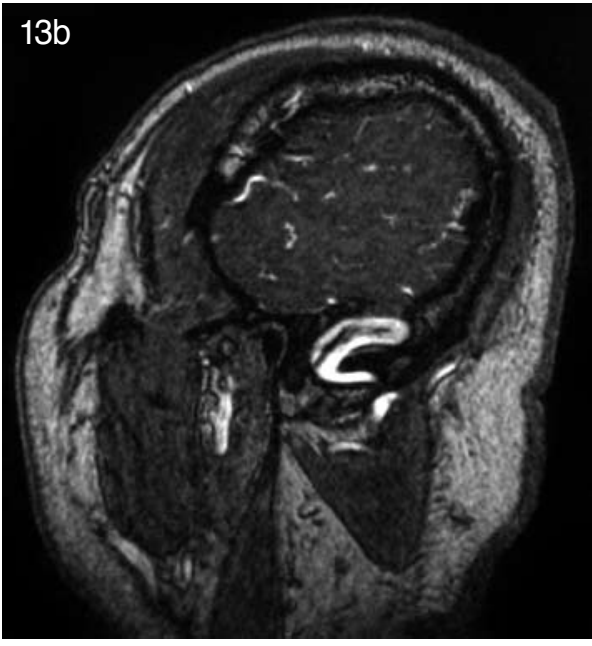

Figura 13. Secuencia ATECO de RM demuestra trombosis del seno lateral con recanalización parcial.

meses $^{(28,29)}$.

\section{Errores frecuentes}

Las variaciones anatómicas a nivel de la confluencia de los senos son frecuentes (Figura 14) ${ }^{(30)}$ y constituyen una causa de falsos positivos. Se describe un $49 \%$ de ST asimétricos, con ausencia parcial o completa en un $20 \%{ }^{(4)}$, lo que puede producir artefactos por flujo lento, rápido o turbulento en $\mathrm{RM}$, incluso en secuencias angiográficas tipo ATECO, dando la falsa impresión de trombosis. La bifurcación asimétrica de la confluencia de los senos o en un nivel superior al habitual puede provocar una imagen triangular llamada "el pseudo delta vacío" (Figura 15) ${ }^{(4,31)}$ reportada en un $18 \%$ de las TC realizadas con contraste.(32) Este error puede evitarse visualizando todo el recorrido de los senos y documentando la densidad de este pseudodefecto, que posee la misma atenuación (TC) o intensidad de señal (RM) que el LCR subaracnoideo.

La presencia de colecciones hipodensas (como abscesos) en el espacio epidural adyacente a los senos, ha sido descrita como posible causa de un "pseudo delta vacío"(31). También se mencionan fenestraciones o septos en el seno dural como causas de falsos positivos ${ }^{(33)}$.

Las granulaciones aracnoideas (Figura 16) se identifican en un $24 \%$ de las TC con contraste ${ }^{(34)}$, usualmente en el SSS y ST, específicamente en su porción lateral (Figuras 17, 18), cerca de la entrada de venas superficiales como la anastomótica inferior (de Labbé)(4), aunque también se encuentran en el seno cavernoso, petroso superior y recto, en orden decreciente de frecuencia ${ }^{(5)}$. Estas pueden protruir directamente en el lumen del seno, pudiendo ser un potencial falso positivo para el signo del delta vacío(5). Una forma de diferenciarlas es considerando su forma redondeada que genera un defecto de llene focal, con la misma atenuación que el LCR subaracnoideo (en 


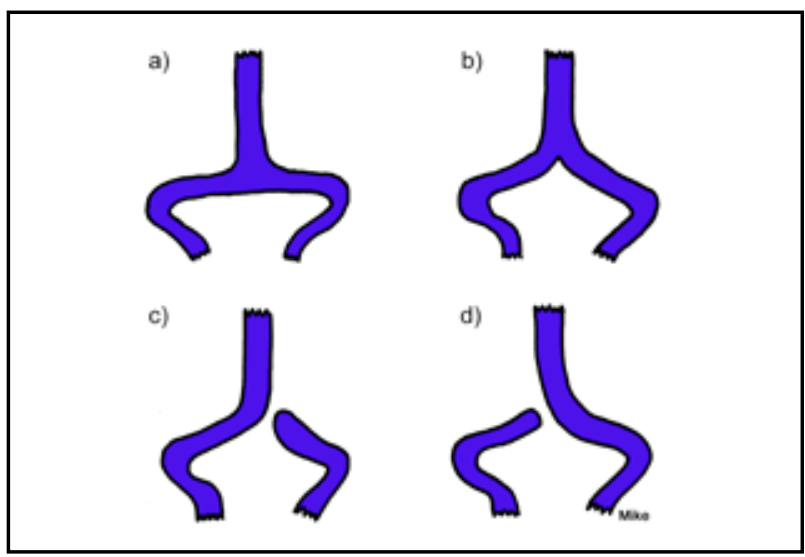

Figura 14. Esquema de visión coronal de las variantes anatómicas encontradas en la confluencia de los senos (Obtenido de referencia 30). a) Confluente: 35\%, b) Bifurcación: $14 \%$, c) Dominancia izquierda: $10 \%$, d) Dominancia derecha: $40 \%$. En los últimos dos tipos hemos observado que el flujo del lado no dominante proviene principalmente de una división del seno recto.

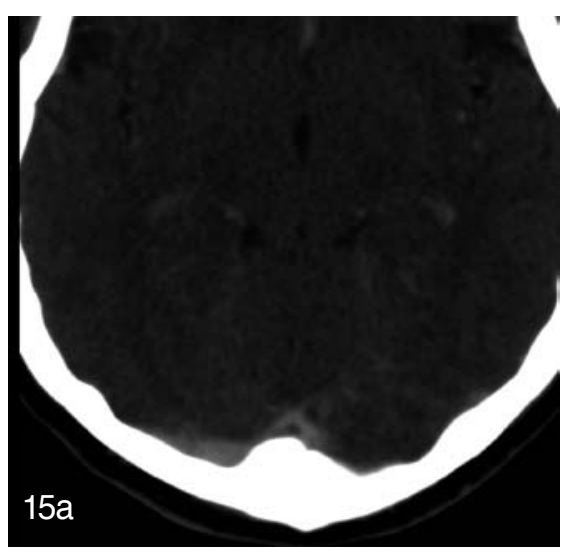

Figura 15. Signo del "pseudo delta vacío". a) En TC con contraste, imagen triangular posterior a la confluencia de los senos, que puede ser malinterpretada como trombosis. b) En la fase sin contraste se demuestra que no hay una imagen hiperdensa. c) La reconstrucción en plano coronal deja manifiesto la configuración de tipo "bifurcación" que tiene la confluencia de los senos.
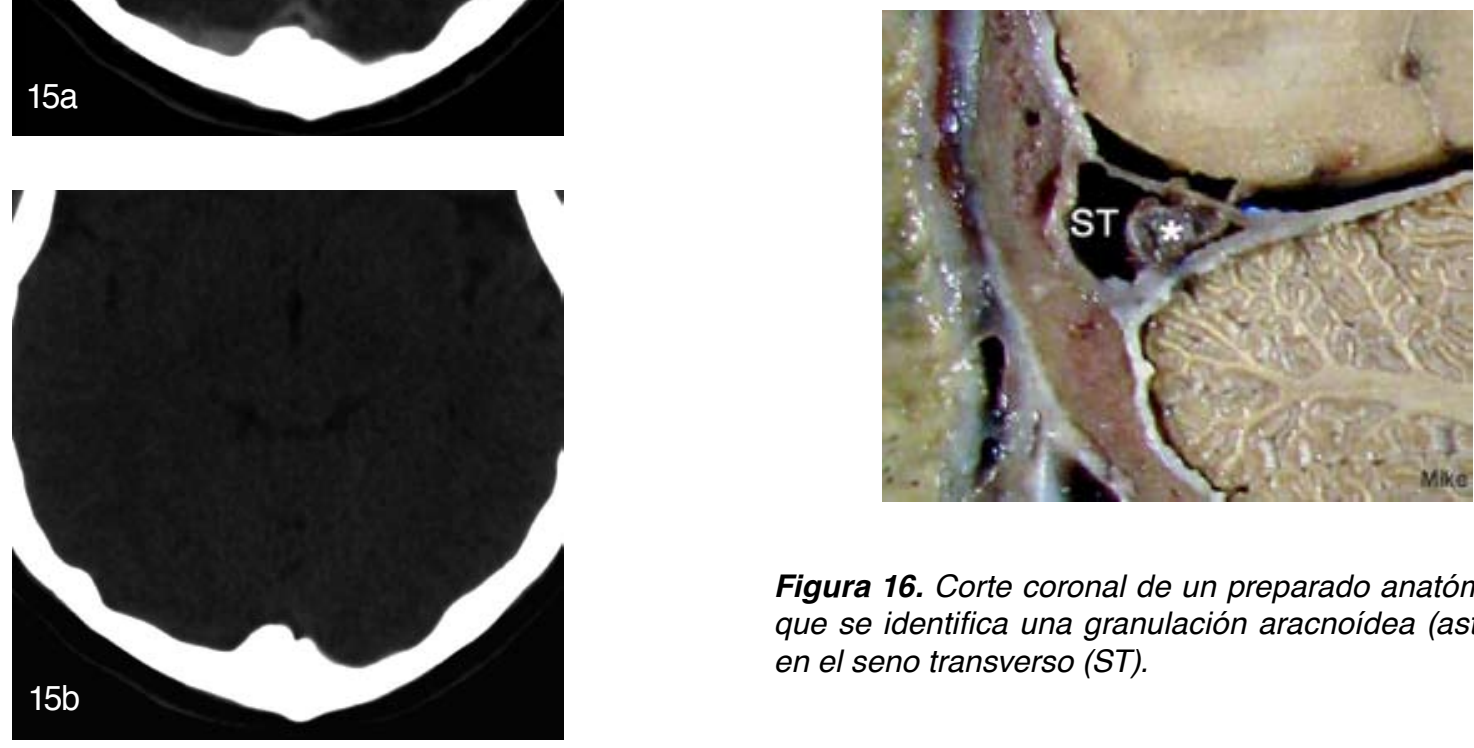

Figura 16. Corte coronal de un preparado anatómico en que se identifica una granulación aracnoídea (asterisco) en el seno transverso (ST).
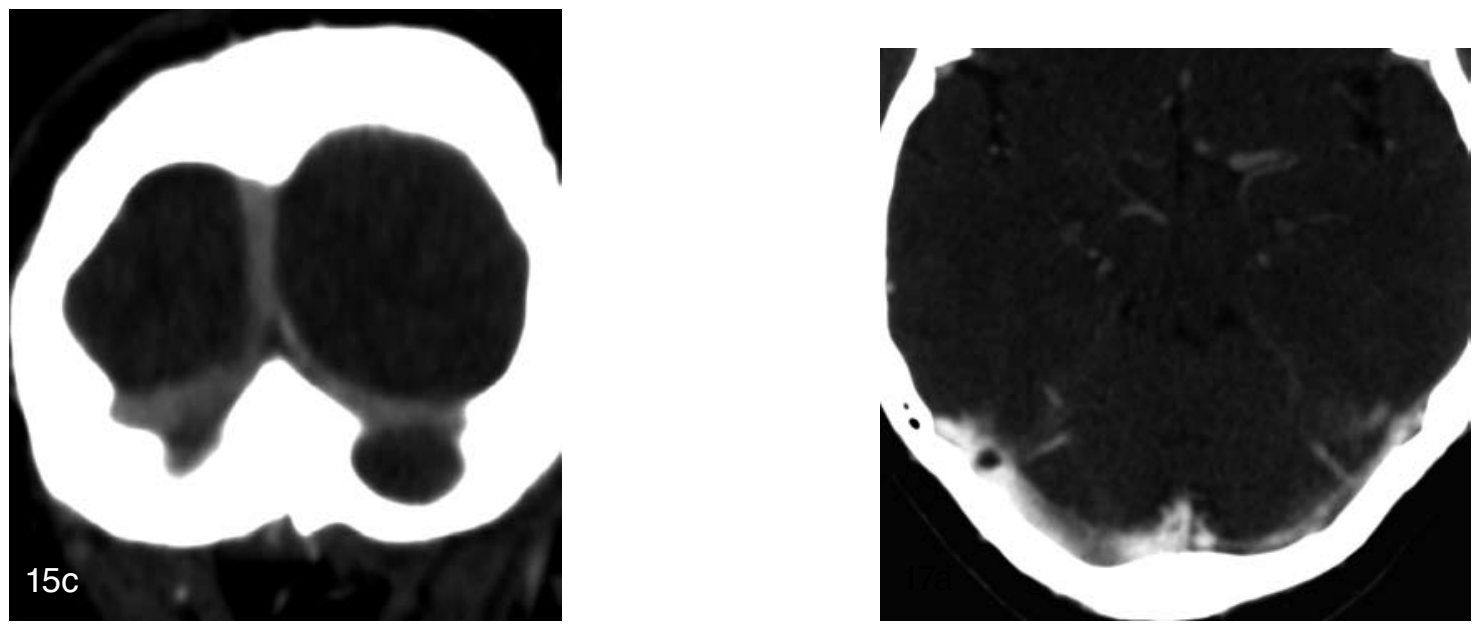

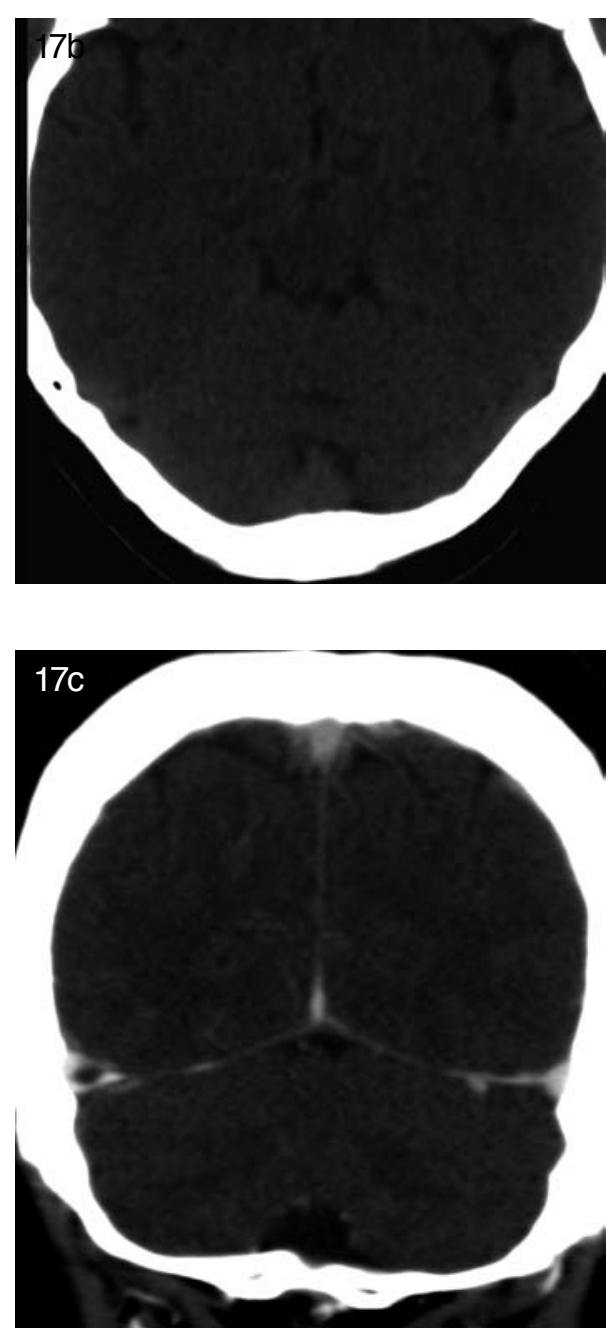

Figura 17. TC a nivel de senos transversos. a) Se identifican defectos de llene característicos de granulaciones aracnoídeas. b) Compárese la densidad del defecto con el seno en la fase sin contraste. c) La reconstrucción en el plano coronal también ayuda a evaluar el defecto.

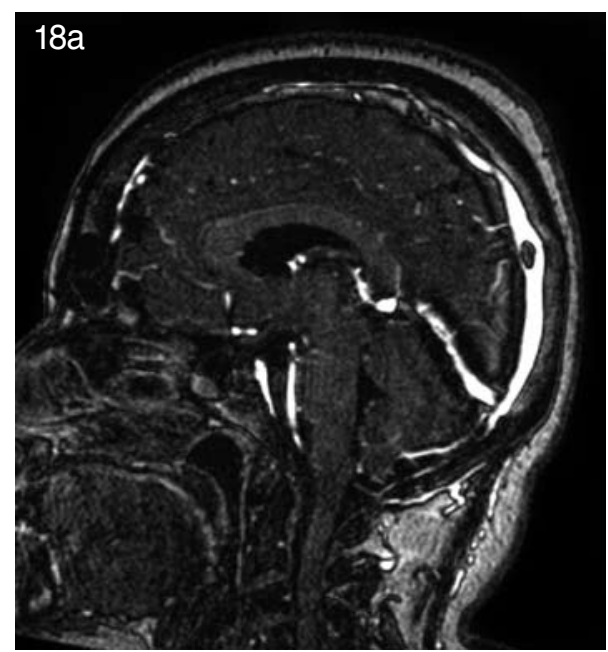

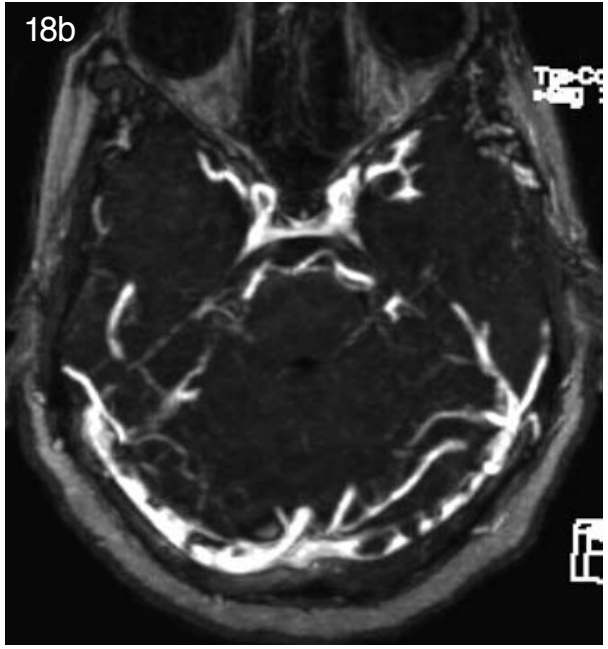

Figura 18. Secuencia ATECO de RM. a) En el plano coronal se observa granulación aracnoidea en el SSS. b) En el mismo paciente se observan granulaciones aracnoideas en el seno transverso.

TC) o intensidad de señal (en RM) $)^{(4)}$.

\section{Comentario final}

Si bien el estudio por angiografía con sustracción digital en fase venosa sigue siendo el "estándar de oro" para el diagnóstico de TVI, método invasivo y no exento de riesgos, se ha buscado la posibilidad de obtener un diagnóstico adecuado mediante metodología no invasiva, como TC o RM. Como ya hemos visto, en estas técnicas existen varios signos que nos permiten hacer el diagnóstico de TVI. A modo de ejemplo, el signo del delta vacío descrito en TC con contraste y también presente en los estudios de RM, es un signo ampliamente conocido por especialistas en imágenes, sin embargo no siempre se conocen los "falsos positivos" que puede originar este signo (variantes anatómicas, granulaciones aracnoidales o flujo lento en RM) ni las condiciones que pueden simular un "falso negativo", como por ejemplo la evolución crónica de un trombo en TC y RM.

Otro punto importante que debemos conocer los radiólogos es la sensibilidad y especificidad de los métodos de imagen y uso de contraste, así como tipo de estudio angiográfico no invasivo de mayor rendimiento en el diagnóstico de una patología de urgencia como la TVI. Es nuestra labor dominar estos conocimientos para así obtener un diagnóstico certero y oportuno, ya que el paciente que está cursando con una TVI se beneficiará enormemente con el tratamiento ${ }^{(5)}$ y en aquel que no lo esté, se evitará un diagnóstico erróneo que lo exponga innecesariamente a un tratamiento anticoagulante, con los riesgos asociados que éste conlleva. Asimismo podemos evitarle un estudio angiográfico convencional a un paciente con un hematoma, al saber reconocer la existencia de una trombosis venosa en estudios de TC y RM.

En resumen, el adecuado conocimiento de los sig- 
nos que permiten hacer el diagnóstico imaginológico de TVI y los errores que pueden originarse por artefactos, condiciones fisiológicas o variantes anatómicas, deben ser conocidos por los radiólogos.

\section{Bibliografía}

1. Stam J. Thrombosis of the Cerebral Veins and Sinuses. N Engl J Med 2005; 352: 1791-1798.

2. Masuhr F, Mehraein S, Einhaupl K. Cerebral venous and sinus thrombosis. J Neurol 2004; 251: 11-23.

3. Lee E. The empty delta sign. Radiology. 2002; 224(3): 788-789.

4. Leach J, Fortuna R, Jones B, Gaskill-Shipley M. Imaging of cerebral venous thrombosis: current techniques, spectrum of findings, and diagnostic pitfalls. Radiographics 2006; Supp 1: S19-41.

5. Rodallec M, Krainik A, Feydy A, Hélias A, Colombani J-M, Jullès M-C, et al. Continuing Medical Education: Cerebral Venous Thrombosis and Multidetector CT Angiography: Tips and Tricks Radiographics 2006; 26: S5-S18.

6. Virapongse C, Cazenave C, Quisling R, Sarwar M, Hunter $S$. The empty delta sign: frequency and significance in 76 cases of dural sinus thrombosis. Radiology 1987; 162 : 779-785.

7. Horowitz M, Greenlee R, Purdy P. Acute and chronic venous sinus thrombosis. In: Batjer HH, eds. Cerebrovascular disease. Philadelphia, Pa: Lippincott-Raven 1997; 559-571.

8. Soleau S, Schmidt R, Stevens S, Osborn A, Mac-Donald $J$. Extensive experience with dural sinus thrombosis. Neurosurgery 2003; 52: 534-544.

9. Ferro J, Canhao P, Stam J, Bousser M, Barinagarrementeria F; ISCVT Investigators. Prognosis of cerebral vein and dural sinus thrombosis: results of the International Study on Cerebral Vein and Dural Sinus Thrombosis (ISCVT). Stroke 2004; 35(3): 664-670.

10. Wetzel S, Kirsch E, Stock K, Kolbe M, Kaim A, Radue E. Cerebral veins: comparative study of CT venography with intraarterial digital subtraction angiography. AJNR Am J Neuroradiol 1999; 20(2): 249-255.

11. Morita S, Ueno E, Masukawa A, Suzuki K, Machida $H$, Fujimura M. Hyperattenuating Signs at Unenhanced CT Indicating Acute Vascular Disease RadioGraphics 2010; 30: 111-125.

12. Macchi P, Grossman R, Gomori J, Goldberg H, Zimmerman R, Bilaniuk L. High field MR imaging of cerebral venous thrombosis. J Comput Assist Tomogr 1986; 10(1): 10-15.

13. Dormont D, Anxionnat R, Evrard S, Louaille C, Chiras J, Marsault C. MRI in cerebral venous thrombosis. J Neuroradiol 1994; 21(2): 81-99.

14. Meckel S, Reisinger C, Bremerich J, Damm D, Wolbers $M$, Engelter S, Scheffler K, Wetzel S. Cerebral Venous Thrombosis: Diagnostic Accuracy of Combined, Dynamic and Static, Contrast-enhanced 4D MR Venography. AJNR Am J Neuroradiol 2010; 31: 527-535.

15. Lettau M, SartorK, Heiland S, Hähnel S. 3T High-SpatialResolution Contrast-Enhanced MR Angiography of the Intracranial Venous System with Parallel Imaging. AJNR Am J Neuroradiol 2009; 30: 185-187.

16. Hu H, Campeau N, Huston J, Kruger D, Haider C, Riederer S. High-Spatial-Resolution Contrast-enhanced MR Angiography of the Intracranial Venous System with
Fourfold Accelerated Two-dimensional Sensitivity Encoding. Radiology 2007; 243 (3): 853-861.

17. Kirchhof K, Welzel T, Jansen O, Sartor K. More Reliable Noninvasive Visualization of the Cerebral Veins and Dural Sinuses: Comparison of Three MR Angiographic Techniques. Radiology 2002; 224: 804-810.

18. Boukobza M, Crassard I, Bousser MG, Chabriat H. MR Imaging Features of Isolated Cortical Vein Thrombosis Diagnosis and Follow-Up. AJNR 2009; 30: 344-248.

19. Idbaih A, Boukobza M, Crassard I, Porcher R, Bousser MG, Chabriat H. MRI of clot in cerebral venous thrombosis high diagnostic value of susceptibility-weighted images. Stroke 2006; 37: 991-95.

20. Bousser MG, Ferro J. Cerebral venous thrombosis: an update. Lancet Neurol 2007; 6: 162-70.

21. Forbes KPN, Pipe JG, Heiserman JE. Evidence for Cytotoxic Edema in the Pathogenesis of Cerebral Venous Infarction. AJNR 2001; 22: 450-455.

22. Rottger C, Trittmacher S, Gerriets T, Bales F, Kaps M, Stotz F. Reversible MR Imaging Abnormalities following Cerebral Venous Thrombosis. AJNR 2005; 26: 607-613.

23. Manzione J, Newman GC, Shapiro A, Santo-Ocampo R. Diffusion- and Perfusion-Weighted MR Imaging of Dural Sinus Thrombosis. AJNR 200; 21: 68-73.

24. Yuh WT, Simonson TM, Wang AM, et al. Venous sinus occlusive disease: MR findings. AJNR 1994;15:309-316

25. Mullins ME, Grant PE, Wang B, Gonzalez RG, Schaefer PW. Parenchymal Abnormalities Associated with Cerebral Venous Sinus Thrombosis: Assessment with DiffusionWeighted MR Imaging. AJNR 2004; 25: 1666-1675.

26. Oppenheim C, Domigo V, GauvritJY, Lamy C, MackowiakCordoliani MA, Pruvo JP, Méder JF. Subarachnoid Hemorrhage as the Initial Presentation of Dural Sinus Thrombosis. AJNR 2005; 26: 614-617.

27. Stolz E, Trittmacher S, Rahimi A, et al. Influence of recanalization on outcome in dural sinus thrombosis. $A$ prospective study. Stroke 2004; 35: 544-547.

28. Dentali F, Gianni M, Crowther M, Ageno W. Natural history of cerebral vein thrombosis: a systematic review. Blood 2006; 108: 1129-1134.

29. Baumgartner RW, Studer A, Arnold M, Georgiadis D. Recanalisation of cerebral venous thrombosis. J Neurol Neurosurg Psychiatry. 2003; 74: 459-461

30. Singh $M$, Nagashima $M$, Inoue $Y$. Anatomical variations of occipital bone impressions for dural venous sinuses around the torcular Herophili, with special reference to the consideration of clinical significance. Surg Radiol Anat 2004; 26: 480-487.

31. Rao K, Knipp H, Wagner E. Computed tomographic findings in cerebral sinus and venous thrombosis. Radiology 1981; 140(2): 391-398.

32. Leach JL. Anatomic variations of the dural venous sinus confluence: appearance on CT with MRI, MRV, and angiographic correlation. Presented at the 34th annual meeting of the American Society of Neuroradiology, Seattle, Washington, June 23-27, 1996.

33. Provenzale J, Joseph G, Barboriak D. Dural sinus thrombosis: findings on CT and MRI imaging and diagnostic pitfalls. AJR 1998; 170: 777-783.

34. Leach J, Jones B, Tomsick T, Stewart C, Balko M. Normal appearance of arachnoid granulations on contrast-enhanced $C T$ and MR of the brain: differentiation from dural sinus disease. AJNR 1996; 17(8): 1523-1532. 